Gore, J. Ecol., 56, 483; 1968) 0.55 K; $13.3 \mathrm{Na} ; 0.67 \mathrm{Ca}$; and $1.92 \mathrm{Mg}$ and on the Lizard Peninsula in Cornwall (Malloch, J. Ecol., 60, 103; 1972) $3.8 \mathrm{~K}$; $19.8 \mathrm{Na} ; 0.9 \mathrm{Ca}$; and $2.0 \mathrm{Mg}$.

The annual uptake of nutrients by the vegetation of the Fire Island forest was determined by measuring the nutrient content of the net primary production in midsummer. The loss of nutrients by litterfall and canopy leaching was found to balance this uptake for most elements, and it would thus seem that the forest is in a climax, equilibrium state. The limitations upon growth in this ecosystem seem to be quite complex. Increased nutrient input would, theoretically, result from a larger tree canopy (that is, greater aboveground-biomass) because this would enhance the impaction component, but this is made impossible by the destruction of emergent shoots by high intensity, salt-laden winds. Vegetative proliferation is possible only by lowlevel lateral branches in the canopy and this seems now to have reached maximum development; as a result a climax has been attained.

In terms of biomass $\left(17,000 \mathrm{~g} \mathrm{~m}^{-2}\right)$ and net primary productivity $(1,100$ $\mathrm{g} \mathrm{m}^{-2}$ ) the Fire Island forest compares well with the figures for temperate forest collected by Rodin and Basilevich (in Functioning of Terrestrial Ecosystems at the Primary Production Level (edit. by Eckardt), Unesco, Paris, 1968). This is despite the extreme nutrient poverty of the sandy substrate. A comparison of nutrient input figures from the Fire Island forest with those from other forest ecosystems shows that the meteorological input alone of several important elements (for example, $\mathbf{K}$ and $\mathrm{Ca}$ ) equals the total (meteorological plus weathering) input of these elements in forests further from the sea. Thus, if nutrient availability is arresting the succession, it is not surprising that the biomass of this 'subclimax' falls little short of that found in climatically limited forests.

Finally, to return to the relation between nutrient availability and the rate of successions, it is interesting to note that the Fire Island forest is considered, on the basis of radiocarbon dating and geological evidence (Sirkin, Bull. Torrey bot. Club, 94, 131; 1972), to be only 200-300 years old. The dune systems around the inland lake Michigan are considered to have taken thousands of years to attain a forested state, but there the low nutrient availability from weathering is accompanied, one presumes, by a low aerial nutrient input. Much more data are needed from such inland dune systems in terms of their nutrient balance, but it seems that there is a strong case for supposing that overall nutrient availability is the factor controlling the rate of succession on those sand dunes. Such a knowledge will undoubtedly provide ammunition for those ecologists who consider that the limiting effects of nutrient supply upon the developmental rate of ecosystems is a general feature of successions (see Nature, 240, 443; 1972).

\section{Repressors at the molecular level}

from Stephen Neidle

THE cluster of three genes responsible for lactose metabolism in Escherichia coli have been perhaps the most intensively studied of all bacterial chromosome systems. Indeed advances in knowledge of this cluster, known as the lac operon, have often tended to be hailed as landmarks in molecular genetics generally. It is now some 13 years since Jacob and Monod first proposed that the control of protein synthesis in bacteria involves certain agents that can repress the relevant genes, and hence inhibit specific messenger RNA synthesis. The first of these substances to be isolated and characterised was the lactose $(l a c)$ repressor, which is a tetrameric protein of molecular weight 150,000 (Gilbert and Müller-Hill, Proc. natn. Acad. Sci. U.S.A., 56, 1891; 1966). These workers followed this considerable technical achievement by demonstrating convincingly that the repressor does indeed act on the lac operator locus of a DNA molecule (ibid., 58, $2415 ; 1967)$.

Detailed knowledge of how repressor proteins turn off DNA at the molecular level, however, is still almost entirely lacking, although some interaction and control models have been proposed, notably by Sobell, Müller-Hill and Gierer. The amino-acid sequence of the $E$. coli lac repressor, as well as the nucleotide sequence of its target on the chromosome, the lac operator, have both been recently determined (ibid., $70,3576 ; 1973)$. Thus, it is not altogether unexpected that protein crystallographers have begun to take an interest in repressor proteins, especially since modern techniques can now provide structural information about such large molecules. Steitz and his colleagues at Yale (ibid., 71, 593; 1974) have succeeded in crystallising the lac repressor, but have obtained disappointingly small microcrystals. Although these are not large enough for even preliminary single-crystal studies, they have revealed a measure of useful information. A combination of powder $\mathrm{X}$-ray diffraction data and electron micrographs has given a good indication of the size and possible symmetry of the unit cell of the protein, as well as that of the tetrameric unit itself. There are four of these tetramers in each orthorhombic repeat, and they appear to be asymmetric and dumbbell in shape, with a length of about 135 $\AA$. It seems most likely that the subunits of the repressor molecule are related by $D_{2}$ point-group symmetry, rather than the four-fold symmetry proposed by Sobell (ibid., 69, 2483; 1972).

This necessarily meagre amount of data has nonetheless enabled Steitz et al. to both reject several of the proposed repressor-DNA operator interaction models, and to suggest one of their own. Any such model has to take into account the two-fold symmetry regions found in the operator nucleotide sequence by Gilbert and Maxam. Rather than binding to either single stranded DNA or four-leaved cloverleaf DNA (both suggested arrangements for the operator locus), the new suggestion is that the dumbbell repressor binds in a manner such that its long axis and the double-helical polynucleotide axis are parallel. The arrangement is described as being similar to a "hotdog in a hotdog bun", which analogy is perhaps clearest to those most familiar with the finer points of the American cuisine. The model has, however, several attractive features, notably that it does not contravene accepted dogma regarding protein-substrate and protein-protein interaction. Also, it has two-fold symmetrical binding grooves, which comply rather well with the operator sequence data.

Until there are more detailed structural studies of both the repressor protein itself, and maybe even complexed with the lac operator fragment of the genome, there will doubtless be numerous more suggested models.
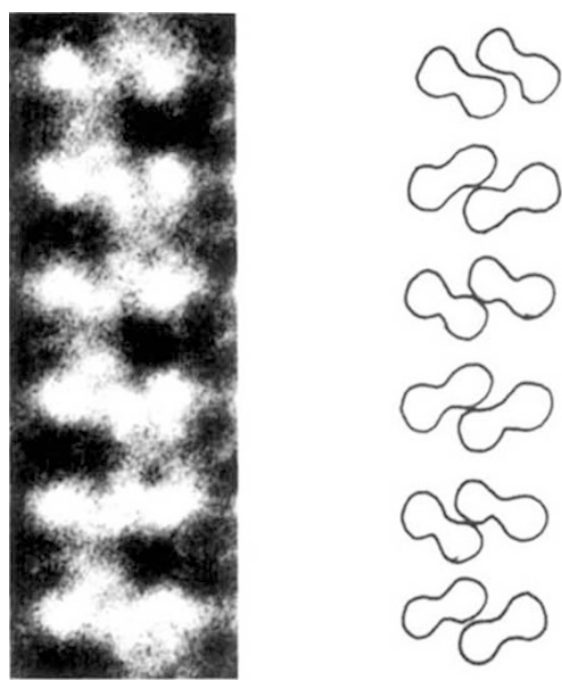

Steitz et al.'s enlargement of part of the translationally averaged election micrograph with, on the right, their interpretation of the molecular outline. Each dumbbell is one repressor tetramer and there are four tetramers per unit cell. 